\title{
Free-Green Synthesis and Dynamics of Reduced Graphene Sheets via Sun Light Irradiation
}

\author{
Nangamso Nathaniel Nyangiwe ${ }^{1 *}$, Mohammed Khenfouch ${ }^{1,2^{*}}$, Force Tefo Thema ${ }^{1,2}$, \\ Kenneth Nukwa ${ }^{1,2}$, Lebogang Kotsedi',2, Malik Maaza ${ }^{1,2}$ \\ ${ }^{1}$ NANOsciences African NETwork (NANOAFNET), iThemba LABS-National Research Foundation of South Africa, \\ Somerset West, South Africa \\ ${ }^{2}$ UNESCO UNISA Africa Chair in Nanosciences-Nanotechnology, College of Graduate Studies, University of \\ South Africa, Pretoria, South Africa \\ Email: " nyangiwenangamso9@gmail, ${ }^{*}$ khenfouch@yahoo.fr
}

Received 8 June 2015; accepted 24 July 2015; published 28 July 2015

Copyright (C) 2015 by authors and Scientific Research Publishing Inc.

This work is licensed under the Creative Commons Attribution International License (CC BY). http://creativecommons.org/licenses/by/4.0/

(c) (i) Open Access

\begin{abstract}
It is universally known that the preparation of high quality graphene on a large scale and in a cost-effective manner is essential for many technological applications. Graphene oxide (G0) has emerged as the precursor of choice for bulk production of graphene-based materials, as it can be synthesized from inexpensive graphite powders. In this paper, a simple method is described for reduction of GO solution by a free and green irradiation based technique. The majority of oxygencontaining functional groups of GO are removed by sun light. This methodology provides an effective way to quantitatively produce high quality graphene sheets. This paper presents irradiation by sun light of synthesized graphene oxide nano-flakes prepared by Hummer's method. These nano-flakes have been successfully reduced while the dynamic of this irradiation process is discussed. The irradiated nano-flakes of graphene oxide have been investigated using X-Ray diffraction, ATR-FTIR and UV-Vis-NIR.
\end{abstract}

\section{Keywords}

Graphene, Graphene Oxide, Nano-Flakes, Sun Light Irradiation

\section{Introduction}

Graphene is an allotrope of carbon, a flat monolayer of carbon atoms tightly packed into a two-dimensional (2D) ${ }^{*}$ Corresponding author. 
honeycomb lattice. By definition it is the basic building block for graphitic materials of all other dimensionalities as shown in Figure 1. Graphene has unique physical, chemical and mechanical properties [1] [2]. It is the first known two-dimensional material which has a singular band structure, and its valence band and conduction band are touching each other [1].

This most talked about material is mostly uncounted in nature in the form of graphite, which is merely a stack of graphene layers held together by van der Waals interactions [1]. It has attracted a lot of interest in the research community [3] [4] due to its potential applications in electrochemical devices, heat insulation, and also as a transparent and flexible semiconductor. A combination of graphene properties makes it suitable as a replacement of the expensive indium tin oxide (ITO) [5]-[7]. Theoretically it is the strongest material ever due to the $\mathrm{sp}^{2} \mathrm{car}^{2}$ bon-carbon bond configuration [1]. Graphene has high electron mobility and electrons can travel freely through it for long distances without being deviated [8]. This makes graphene a very appealing material for fast transistors [8]. It is universally known that the preparation of high quality graphene on a large scale and in a cost-effective manner is essential for many technological applications. Graphene oxide (GO) has emerged as the precursor of choice for bulk production of graphene- based materials, as it can be synthesized from inexpensive graphite powders. Several techniques have been developed to reduce GO to graphene, including chemical reduction and thermal annealing. Recently, photo reduction of GO has been carried out using flash reduction irradiation with a $663 \mathrm{~nm}$ continuous-wave (CW) laser as well as a $790 \mathrm{~nm}$ femto-second laser irradiation. Unfortunately, the effective reducing agents are generally toxic while the laser based photo-reduction techniques are expensive.

In this paper, a simple method is described for reduction of GO solution by a free and green irradiation based technique. The majority of oxygen-containing functional groups of GO are removed by sun light. This methodology provides an effective way to quantitatively produce high quality graphene sheets via the solar irradiation of graphene oxide solutions.

\section{Chemical Reduction of Graphene Oxide Nano-Sheets}

As it is shared by various scientific disciplines, stretching from cosmology to material sciences, Carbon and Hydrogen are among the universal and basic elements of the Mendeleev periodic table. Carbon possesses various allotropes including diamond, graphitic carbon, carbon nanotubes, fullerenes, and the recently synthesized graphene. Graphene nanosheets are atomically thick, 2-D platelets exhibiting carbon atoms in hexagonal honeycomb arrangements [1]. These $\mathrm{sp}^{2}$ hybridized atomic scaled sheets of Carbon possess a substantial set of unique desirable properties. This latter singular set includes a large mechanical stiffness of about $1 \mathrm{TPa}$ [2], a significant thermal conductivity of the order of $5 \times 10^{3} \mathrm{~W} / \mathrm{m}^{-1} \cdot \mathrm{K}^{-1}[3]$ and an exceptional charge carrier mobility of the order of $25 \times 10^{4} \mathrm{~cm}^{2} / \mathrm{V}^{-1} \cdot \mathrm{s}^{-1}[4]$.

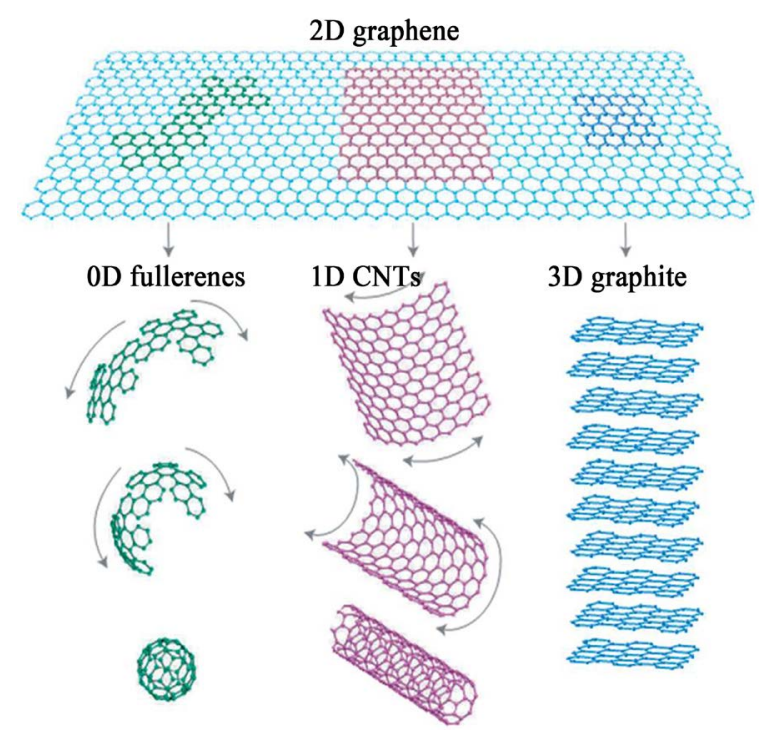

Figure 1. Shows graphene sheet as the building block of all graphitic forms, it can be wrapped into a 0-D (buckyballs), 1-D (nanotubes) and stacked to form the 3-D (graphite). 
Consequentially, graphene is being studied for various promising and potential use in a variety of physicalchemical applications that exploit these remarkable properties [5] [6] ranging from gas sensors [7] to lithium-ion battery electrodes including the emerging graphene based transparent electrodes field [8] [9].

As well established, the primary synthetic procedure for producing processable quantities of colloidal graphene, known also as highly reduced graphene oxide (HRGO) [10], entails the reduction of aqueous or organic dispersions of GO [11], a highly oxidized derivative of graphene possessing various oxygen-containing functional groups such as epoxy, hydroxyl, carbonyl, and carboxyl [12]-[16]. These groups, noticed on both the edge as well as on the basal plane of the nanosheets, acquaint $\mathrm{sp}^{3}$ defect sites to the nanosheets, distorting the intrinsic conjugated $\pi$ system and bringing down the overall strength and electrical conductivity [17].

The reactivity of these groups creates graphene oxide nanosheets extremely attractive as building blocks for a wide range of macroscopic structures, as they can be readily functionalized and or modified with a variety of surfactants [18] [19]. Current reduction methods for producing graphene nano-suspensions from graphene oxide typically afford nanosheets with high C/O ratios $\left(\sim 10^{10}\right)$ that exhibit good electrical conductivity, but are effectively inactive for chemical functionalization due to the low density of reactive groups remaining on the sheet surface. The main approach comprises the full exfoliation of GO into individual GO sheets followed by their in-situ reduction to produce individual graphene-like sheets.

More precisely, GO is synthesized by the oxidative treatment of graphite via one of three principal methods developed by Brodie [18], Hummers [19], and Staudenmeier [20], respectively. It still keeps a layered structure, but is very lighter in color than graphite due to the loss of electronic conjugation brought about by the oxidation phase. Compared to HRGO sheets, and according to the most recent studies [21]-[25], GO comprises of oxidized graphene sheets having their basal planes decorated mostly with epoxide and hydroxyl groups, in addition to carbonyl and carboxyl groups located presumably at the edges (Lerf-Klinowski model). These oxygen functionalities provide the graphene oxide layers of GO hydrophilic and water molecules can readily intercalate into the interlayer galleries. GO can therefore be considered of as a graphite-type intercalation compound with both covalently bound oxygen and non-covalently bound water between the carbon layers. Indeed, rapid heating of GO results in its expansion and delamination caused by rapid evaporation of the intercalated water and evolution of gases produced by thermal pyrolysis of the oxygen-containing functional groups [26].

Such thermal treatment has recently been proposed to be capable of making individual functionalized graphene sheets. GO is electrically insulating and thus cannot be used, without further processing, as a conductive nanomaterial. On top of that, the existence of the oxygen functional groups makes GO thermally unstable, as it undergoes pyrolysis at high temperatures [27] [28]. Notably, it has been exhibited that the electrical conductivity of GO can be revived close to the level of graphite by chemical reduction [26]. The research of reductions of GO is still at an early stage. To that end, various chemical reductions of exfoliated graphene oxide sheets with several reducing agents were carried out and it was that found hydrazine hydrate $\left(\mathrm{H}_{2} \mathrm{NNH}_{2}-\mathrm{H}_{2} \mathrm{O}\right)$ to be the best one in producing very thin graphene-like sheets, consistent with previous reports of Stankovich et al. [16] [29].

\section{Light Photo-Induced Reduction of Graphene Oxide Nano-Sheets}

Given the worldwide interest in the large scale preparation of graphene-based materials [6], the international concerned community set out to develop a general and reproducible approach for the preparation of graphene sheets from graphite at a mass scale and a competitive cost. Yet, this latter strategy is based on GO or HRGO as basic graphene precursors. The usage of light as a mean to reduce GO nano-flakes to graphene nano-sheets is an attractive path. Indeed, laser induced graphite oxide/graphene transformation in films was confirmed by Liu et al. [30], Sokolov et al. [31], and Zhang et al. [32]. In addition, Trusovas et al. [33] have recently demonstrated the direct local formation of few layers of graphene by direct laser writing on thin films of graphene oxide in the pico-regime.

More precisely, with a standard NdYAG irradiation of a fluence varying between $0.01 \mathrm{~J} / \mathrm{cm}^{2}$ to $0.3 \mathrm{~J} / \mathrm{cm}^{2}$ and a repetition rate of about $100 \mathrm{kHz}$ in air, the resistance of the GO decreases by 4 to 5 orders of magnitude. By conducting additional experiments in nitrogen and argon atmosphere, they have succeeded to achieve higher $\mathrm{I}_{2 \mathrm{G}} / \mathrm{I}_{\mathrm{D}}$ ratio in Raman spectra. In the femto-regime, Zhang et al. demonstrated the direct imprinting of microcircuits of graphene on graphene oxide films by femtosecond laser reduction. More precisely, it was clearly evidenced that the surface height of the micro-patterns was lower than the rest of the film due to the loss of oxy- 
gen's as confirmed by XPS and XRD investigations. The corresponding electric resistivity and conductivity of reduced graphene were found to have a strong dependence on the output of the femtosecond laser source while the current-voltage of the synthesized graphene based micro-circuits showed typical linear relationship, indicating the stable conductivities. Overall, the laser irradiation reduction of graphene oxide might have a way to graphene based nano-electronics.

In addition to IR laser reduction of GO in both femto and picosecond regimes as previously highlighted, Rao et al. [34] extended the study to VIS and UV laser radiations based reduction. More specifically, effect of irradiation on graphene oxide by UV radiation based light and KrF excimer laser has been investigated. Ultraviolet light reduce graphene oxide well after prolonged irradiation, yet the $\mathrm{KrF}$ laser irradiation produces graphene with negligible oxygen functionalities within a relatively short time.

In this study, the graphite oxide was prepared by the standard modified Hummer's method with graphite oxide readily forming a stable colloidal suspension in water. The aqueous suspension was subjected to ultrasonic treatment. The GO solution was taken in glass tubes which were exposed to sun light for a few hours. In such experiments, the initial GO solution in water medium was brownish yellow in color. It gradually turned reddish after about $2 \mathrm{~h}$ of irradiation. It finally turned black in color after $10 \mathrm{~h}$ of irradiation. The color change of the graphene oxide from brownish yellow to black was a clear evidence of the occurrence of reduction phenomenon. From the IR spectra, it was observed that the intensity of the carbonyl stretching band decreased substantially after 10 hour irradiation. Similarly, the intensities of bands due to other oxygen containing functional groups also decreased after the prolonged irradiation.

Through a careful ATR-FTIR investigation, it was observed that the intensity of the carbonyl stretching band in the IR spectrum decreased markedly after irradiation for $2 \mathrm{~h}$. Bands due to other oxygen containing functional groups disappeared upon irradiation. The brownish yellow colour of the graphene oxide solution started to become deeper brownish red even after short irradiation.

This concurred with the near disappearance of the carbonyl stretching band as well as of other bands due to oxygen functionalities after $2 \mathrm{~h}$ of irradiation in the IR spectrum.

\section{Synthesis of Graphene Oxide Nano-Sheets}

The graphite used in this work was purchased from Sigma-Aldrich. We synthesized graphene nanopowder using Hummers method which involved the exfoliation of graphite in the presence of strong acids and oxidants as described earlier. More specifically, $1.5 \mathrm{~g}$ of natural flake graphite powder was added to $35 \mathrm{ml}$ of cold $\left(0^{\circ} \mathrm{C}\right)$ concentrated $\mathrm{H}_{2} \mathrm{SO}_{4}$. Then, $4.5 \mathrm{~g}$ of $\mathrm{KMnO}_{4}$ was added gradually with stirring and cooling in an ice bath. The mixture was then stirred at $40^{\circ} \mathrm{C}$ for $2 \mathrm{~h}$. Distilled water $(70 \mathrm{ml})$ was slowly added to the mixture and the temperature of the mixture was maintained below $100^{\circ} \mathrm{C}$ for about $15 \mathrm{~min}$. After that, $210 \mathrm{ml}$ of $30 \% \mathrm{H}_{2} \mathrm{O}_{2}$ solution was added to the mixture. Finally, the product was filtered with $400 \mathrm{ml}$ of $10 \% \mathrm{HCl}$ aqueous solution to remove metal ions and then thoroughly washed five times with distilled water. Diluted solution of few layered graphene oxide (FLGO) was prepared by the dispersion (via ultrasound for 1 hour) of $0.1 \mathrm{~g}$ of the brown yellow powder in $200 \mathrm{ml}$ of distilled water. For samples preparation we filled glass tubes with $10 \mathrm{ml}$ of FLGO solution for been exposed to sun light.

\section{Results and Discussion}

\subsection{X-Rays Diffraction Investigations}

The crystallinity of the reduced graphene oxide by sun light was investigated and compared with graphene oxide via the X-rays Diffraction (XRD) patterns of dried films deposited onto silicon substrates. Figure 2 depicts typical XRD profiles of this exposure.

The comparison of the typical peaks observed for the GO and RGO films showed the disappearance of GO peak and the appearance of peaks characteristics of reduced graphene oxide which found to be agglomerated as confirmed by the narrow FWHM of its peaks.

The peak located at around $2 \theta=21^{\circ}$ corresponds to the (100), suggested significant changes in the crystal structure of GO and confirmed the reduction of GO. In addition, several oxygen functionalities were reduced from the basal plan and afforded reduced GO structure with interlayer spacing of $0.41 \mathrm{~nm}\left(2 \theta=23^{\circ}\right)$ corresponding to the diffraction of the (002) plane.

The dynamic of this reduction can be followed by the ratio of the two intensities $I_{1} / I_{2}$ (related to the mentioned peaks) which increase value with the time of exposition due to the minimization of oxygen incorporation. 


\subsection{ATR-FTIR Spectroscopy Investigations}

Figure 3 depicts a typical ATR-FTIR patterns of GO irradiated by sun light for different durations. From the ATR-FTIR spectra, we see that the intensity of the carbonyl stretching band decreases substantially after 2 hours irradiation.

Similarly, the intensities of other bands due to other oxygen containing functional groups also decrease after the prolonged irradiation. At $1620 \mathrm{~cm}^{-1}$ (skeletal vibrations from un-oxidized graphitic domains), at $1220 \mathrm{~cm}^{-1}$ (C-OH stretching vibrations), at $1060 \mathrm{~cm}^{-1}$ (C-O stretching vibrations), and stretching vibrations from $\mathrm{C}=\mathrm{O}$ at $1720 \mathrm{~cm}^{-1}$ due to the remaining of carboxyl groups and the vibration modes of epoxide (C-O-C) at (1230 - 1320 $\mathrm{cm}^{-1}$, asymmetric stretching at $850 \mathrm{~cm}^{-1}$, bending motion).

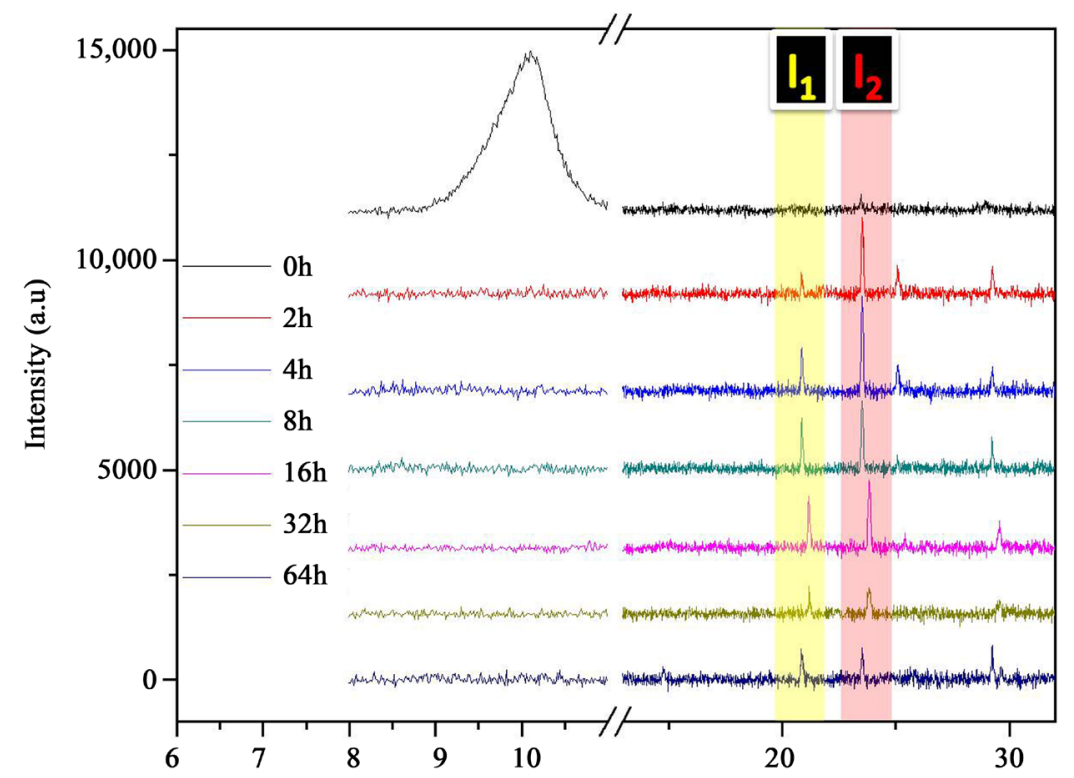

(20)

Figure 2. Typical XRD patterns of sun light irradiated GO for different durations.

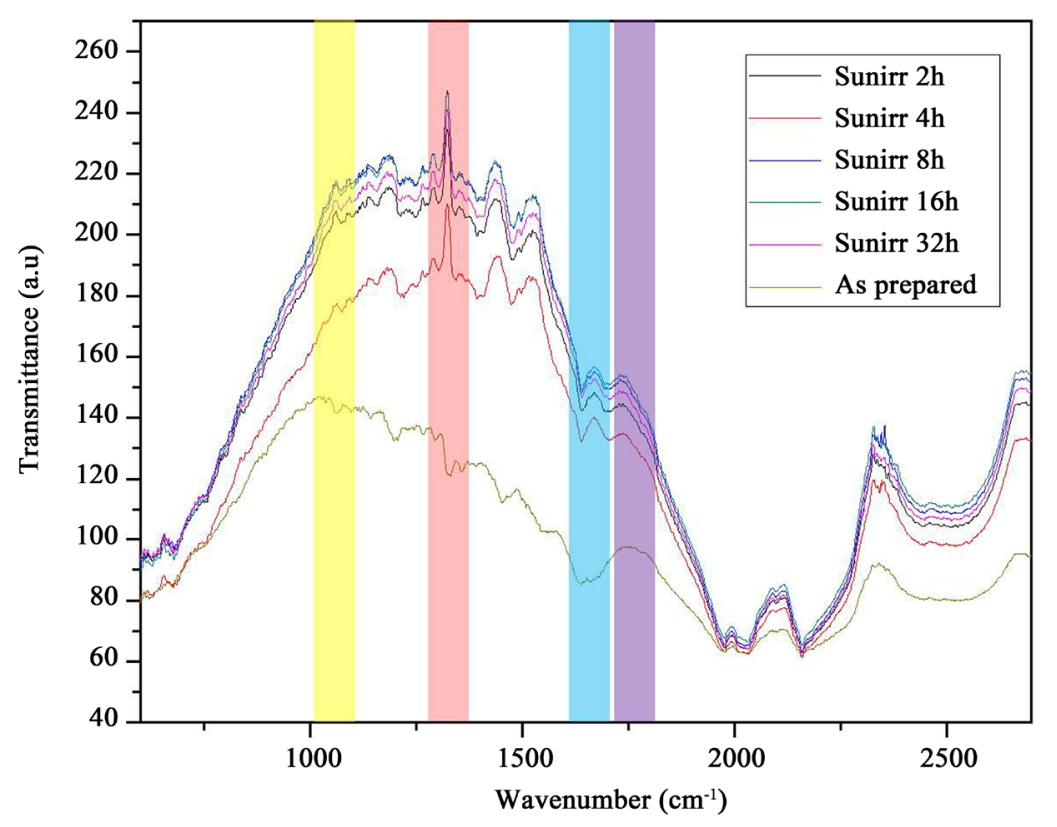

Figure 3. Typical ATR-FTIR patterns of GO irradiated by sun light for different durations. 


\subsection{UV-VIS-NIR Absorbance Spectroscopy Investigations}

Figure 4 depicts the UV-VIS-NIR absorbance spectra of the various photo-reduced GO nano-solutions under sun light for various exposure time. In all corresponding spectra, the specific absorbance in the UV-VIS-NIR range quasi-disappear and are smoothened on a wide spectral range. This behavior seems to start at about the threshold exposure time of about 4 . After $8 \mathrm{~h}$ of irradiation, it seems that there is a stabilization of the photo- reduction process.

The color change of the graphene oxide from brownish yellow to black is a clear evidence of the occurrence of reduction via sun light irradiation. Hence, the dynamic of photo-reduction by this radiation can be followed easily with UV-UVIS-NIR absorbance spectroscopy. Indeed, the GO absorbance spectrum is known by the presence of three principal peaks, the main absorbance peak attributed to the $\pi \rightarrow \pi^{*}$ transitions of C-C occurs at around $225 \mathrm{~nm}$, the broad absorption spectra extended up to $1500 \mathrm{~nm}$ indicating a well-defined band-edge in the UV-VIS-NIR energy range and a shoulder around $320 \mathrm{~nm}$ may be attributed to the $\pi \rightarrow \pi^{*}$ transitions of C-O. The Transformation of GO in our samples, reduced by sun light, is confirmed by the slow disappearance of C-C band centered at around $225 \mathrm{~nm}$ and its shifting to $260 \mathrm{~nm}$ upon exposition time most likely due to the decrease in the concentration of carboxyl groups shown in Figure 3 indicating that the electronic conjugation within the reduced graphene sheets was revived upon reduction of graphene oxide.

When graphitic materials which can undergo chemical transformations are irradiated with a light source, there can be three possible effects: a) light radiation does not get absorbed by the material (in this case, solid-liquid interface will be heated); b) it gets absorbed but is not sufficient for the chemical transformation and c) it is utilized for the chemical transformation. Distinguishing between the possible reduction mechanisms and understanding their dynamics is challenging but is important from both a fundamental and applied point of view. While the thermal reduction of GO is universally known, its photoinduced reduction mechanism still attracting researchers. Hence, some processes were proposed to understand this photoinduced transformation. A recent model was proposed [35] for GO photoreduction in water: the ultraviolet light $(4.6 \mathrm{eV})$ is absorbed by the solvent through a nonlinear process. This process excites the water above its photoionization threshold $(6.5 \mathrm{eV})$ leading to the generation of solvated electrons [36], which are then responsible for the production of rGO.

The process which could be at the origin of this photo-induced reduction can be described by the following reaction equations

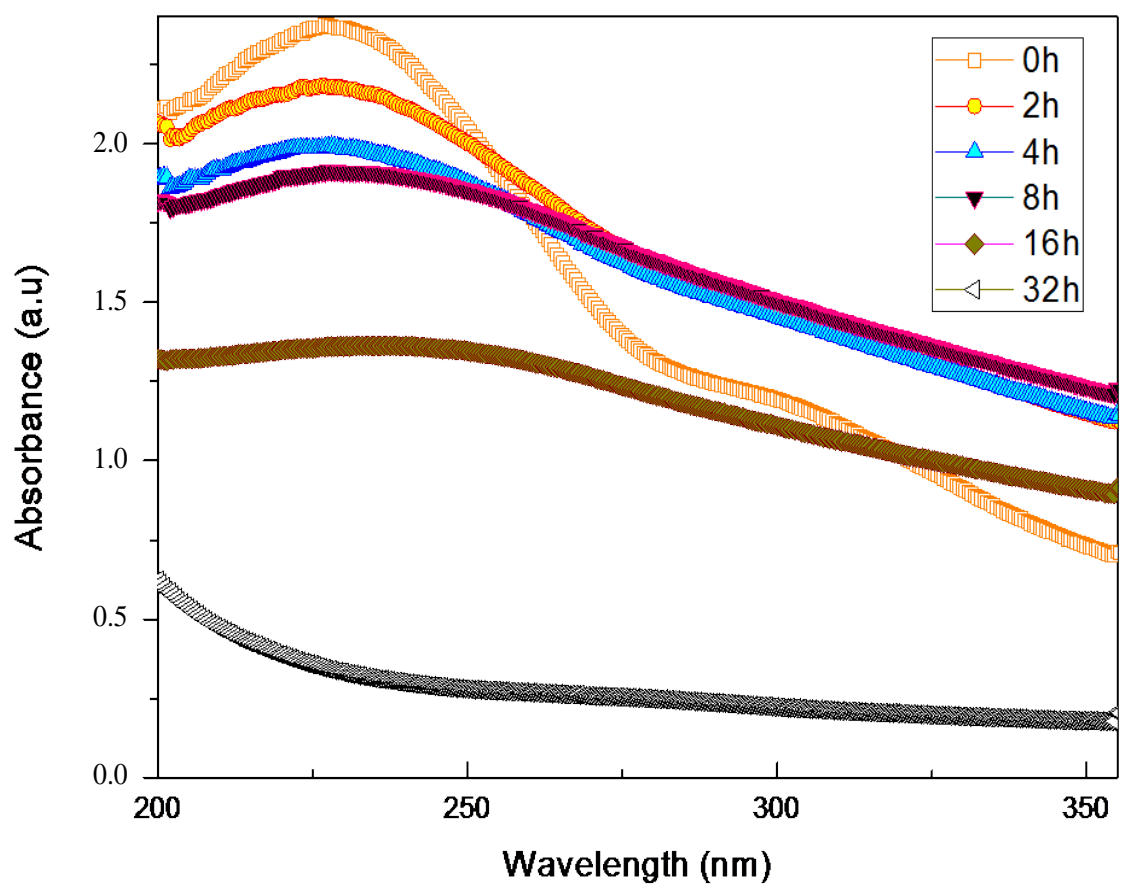

Figure 4. Typical UV-VIS-NIR absorbance spectra of GO irradiated by sun light for different durations. 


$$
\begin{aligned}
& \mathrm{GO}+\mathrm{H}_{2} \mathrm{O}+2 \mathrm{hv} \rightarrow \mathrm{GO}^{*}+\mathrm{H}_{2} \mathrm{O}^{*} \\
& \mathrm{GO}^{*}+\mathrm{H}_{2} \mathrm{O}^{*} \rightarrow \mathrm{GO}+\mathrm{OH}_{\mathrm{aq}}+\mathrm{H}_{3} \mathrm{O}^{+} \\
& \mathrm{GO}+\mathrm{OH}_{\mathrm{aq}}+\mathrm{H}_{3} \mathrm{O}^{+}+\mathrm{e}^{-} \rightarrow \text { Reduced } \mathrm{GO}+\mathrm{H}_{2} \mathrm{O}
\end{aligned}
$$

In addition, this process sustains the explanation of Rao et al. through a 3 steps mechanism.

$$
\begin{aligned}
& \mathrm{GO}+\mathrm{hv} \rightarrow \mathrm{GO}(\text { hole }+\mathrm{e}) \\
& 4 \text { holes }+2 \mathrm{H}_{2} \mathrm{O} \rightarrow \mathrm{O}_{2}+4 \mathrm{H}^{+} \\
& 4 \mathrm{e}+\mathrm{GO}+4 \mathrm{H}^{+} \rightarrow \text { Reduced } \mathrm{GO}+2 \mathrm{H}_{2} \mathrm{O}
\end{aligned}
$$

\section{Conclusion}

From this experiment the authors managed to irradiate graphene nano-flakes under sun light to produce graphene sheets solutions. Although sun light irradiation is an attractive approach, there are some factors that restrain its performance. The sun radiations are carried out successfully and the most interesting results are obtained after 4 hours treatment. This methodology provides an effective way to quantitatively produce high quality graphene sheets.

\section{Acknowledgements}

The author would like to thank the National Research Foundation, iThemba LABS Materials Research Department for funding this project.

\section{References}

[1] Owen, C., Bonny, J., Dmitriy, A., Dikin, A., Khalil, A., Son, B. and Nguyen, T. (2011) Chemically Active Reduced Graphene Oxide with Tunable C/O Ratios. ACS Nano, 5, 4380-4391.

[2] Lee, C.G., Wei, X.D., Kysar, J.W. and Hone, J. (2008) Measurement of the Elastic Properties and Intrinsic Strength of Monolayer Graphene. Science, 321, 385-388. http://dx.doi.org/10.1126/science.1157996

[3] Balandin, A.A., Ghosh, S., Bao, W.Z., Calizo, I., Teweldebrhan, D., Miao, F. and Lau, C.N. (2008) Superior Thermal Conductivity of Single-Layer Graphene. Nano Letters, 8, 902-907. http://dx.doi.org/10.1021/nl0731872

[4] Orlita, M., Faugeras, C., Plochocka, P., Neugebauer, P., Martinez, G., Maude, D.K., Barra, A.L., Sprinkle, M., Berger, C., de Heer, W.A., et al. (2008) Approaching the Dirac Point in High-Mobility Multilayer Epitaxial Graphene. Physical Review Letters, 101, Article ID: 267601. http://dx.doi.org/10.1103/PhysRevLett.101.267601

[5] Chen, H.Q., Müller, M.B., Gilmore, K.J., Wallace, G.G. and Li., D. (2008) Mechanically Strong, Electrically Conductive, and Biocompatible Graphene Paper. Advanced Materials, 20, 3557-3561. http://dx.doi.org/10.1002/adma.200800757

[6] Stankovich, S., Dikin, D.A., Dommett, G.H.B., Kohlhaas, K.M., Zimney, E.J., Stach, E.A., Piner, R.D., Nguyen, S.T. and Ruoff, R.S. (2006) Graphene-Based Composite Materials. Nature, 442, 282-286. http://dx.doi.org/10.1038/nature04969

[7] Fowler, J.D., Allen, M.J., Tung, V.C., Yang, Y., Kaner, R.B. and Weiller, B.H. (2009) Practical Chemical Sensors from Chemically Derived Graphene. ACS Nano, 3, 301-306. http://dx.doi.org/10.1021/nn800593m

[8] Wang, C.Y., Li, D., Too, C.O. and Wallace, G.G. (2009) Electrochemical Properties of Graphene Paper Electrodes Used in Lithium Batteries. Chemistry of Materials, 21, 2604-2606. http://dx.doi.org/10.1021/cm900764n

[9] Abouimrane, A., Compton, O.C., Amine, K. and Nguyen, S.T. (2010) Non-Annealed Graphene Paper as a Binder-Free Anode for Lithium-Ion Batteries. The Journal of Physical Chemistry C, 114, 12800-12804. http://dx.doi.org/10.1021/jp103704y

[10] Park, S., An, J.H., Jung, I.W., Piner, R.D., An, S.J., Li., X.S., Velamakanni, A. and Ruoff, R.S. (2009) Colloidal Suspensions of Highly Reduced Graphene Oxide in a Wide Variety of Organic Solvents. Nano Letters, 9, 1593-1597. http://dx.doi.org/10.1021/nl803798y

[11] Park, S. and Ruoff, R.S. (2009) Chemical Methods for the Production of Graphenes. Nature Nanotechnology, 4, 217224. http://dx.doi.org/10.1038/nnano.2009.58

[12] Lerf, A., He, H., Forster, M. and Klinowski, J. (1998) Structure of Graphite Oxide Revisited. The Journal of Physical Chemistry B, 102, 4477-4482. 
[13] Cai, W., Piner, R.D., Stadermann, F.J., Park, S., Shaibat, M.A., Ishii, Y., Yang, D.X., Velamakanni, A., An, S.J. and Stoller, M. (2008) Synthesis and Solid-State NMR Structural Characterization of 13C-Labeled Graphite Oxide. Science, 321, 1815-1817. http://dx.doi.org/10.1126/science.1162369

[14] Szabo, T., Berkesi, O., Forgo, P., Josepovits, K., Sanakis, Y., Petridis, D. and Dekany, I. (2006) Evolution of Surface Functional Groups in a Series of Progressively Oxidized Graphite Oxides. Chemistry of Materials, 18, 2740-2749. http://dx.doi.org/10.1021/cm060258+

[15] Compton, O.C. and Nguyen, S.T. (2010) Graphene Oxide, Highly Reduced Graphene Oxide, and Graphene: Versatile Building Blocks for Carbon-Based Materials. Small, 6, 711-723. http://dx.doi.org/10.1002/smll.200901934

[16] Stankovich, S., Piner, R.D., Nguyen, S.T. and Ruoff, R.S. (2006) Synthesis and Exfoliation of Isocyanate Treated Graphene Oxide Nanoplatelets. Carbon, 44, 3342-3347. http://dx.doi.org/10.1016/j.carbon.2006.06.004

[17] Niyogi, S., Bekyarova, E., Itkis, M.E., McWilliams, J.L., Hamon, M.A. and Haddon, R.C. (2006) Solution Properties of Graphite and Graphene. Journal of the American Chemical Society, 128, 7720-7721.

[18] Brodie, B.C. (1960) Sur le poids atomique du graphite. Annales de Chimie et de Physique, 59, 466-472.

[19] Hummers, W. and Offeman R. (1958) Preparation of Graphitic Oxide. Journal of the American Chemical Society, 80, 1339.

[20] Staudenmaier, L. (1898) Verfahren zur Darstellung der Graphitsäure. Berichte der deutschen chemischen Gesellschaft, 31, 1481-1499. http://dx.doi.org/10.1002/cber.18980310237

[21] He, H., Riedl, T., Lerf, A. and Klinowski, J. (1996) Solid-State NMR Studies of the Structure of Graphite Oxide. The Journal of Physical Chemistry, 100, 19954-19958.

[22] He, H., Klinowski, J., Forster, M. and Lerf, A. (1998) A New Structural Model for Graphite Oxide. Chemical Physics Letters, 287, 53-56.

[23] Lerf, A., He, H., Riedl, T., Forster, M. and Klinowski, J. (1997) 13C and 1H MAS NMR Studies of Graphite Oxide and Its Chemically Modified Derivatives. Solid State Ionics, 101-103, 857-862.

[24] Szabo, T., Berkesi, O. and Dekany, I. (2005) DRIFT Study of Deuterium-Exchanged Graphite Oxide. Carbon, 43, 3186-3189.

[25] Hontoria, L., Lopez, P., Lopez, G., Rojas, C. and Martin, A. (1995) Study of Oxygen-Containing Groups in a Series of Graphite Oxides: Physical and Chemical Characterization. Carbon, 33, 1585-1592.

[26] Boehm, H.P., Clauss, A., Fischer, G.O. and Hofmann, U. (1962) The Adsorption Behavior of Very Thin Carbon Films. Zeitschrift für anorganische und allgemeine Chemie, 316, 119-127. http://dx.doi.org/10.1002/zaac.19623160303

[27] Bourlinos, A.B., Gournis, D., Petridis, D., Szabo, T., Szeri, A. and Dekany, I. (2003) Graphite Oxide: Chemical Reduction to Graphite and Surface Modification with Primary Aliphatic Amines and Amino Acids. Langmuir, 19, 60506055 .

[28] Boehm, H.P., Clauss, A., Fischer, G.O. and Hofmann, U. (1962) Thin Carbon Leaves. Zeitschrift für Naturforschung, 17b, 150-153.

[29] Stankovich, S., Piner, R.D., Chen, X., Wu, N., Nguyen, S.T. and Ruoff, R.S. (2006) Stable Aqueous Dispersions of Graphitic Nanoplatelets via the Reduction of Exfoliated Graphite Oxide in the Presence of Poly(sodium 4-styrenesulfonate). Journal of Materials Chemistry, 16, 155-158.

[30] Liu, Z.B., Li, L., Xu, Y.F., Liang, J.J., Zhao, X., Chen, S.Q., Chen, Y.S. and Tian, J.G. (2011) Direct Patterning on Reduced Graphene Oxide Nanosheets Using Femtosecond Laser Pulses. Journal of Optics, 13, Article ID: 085601. http://dx.doi.org/10.1088/2040-8978/13/8/085601

[31] Sokolov, D.E., Shepperd, K.R. and Orlando, T.M. (2010) Formation of Graphene Features from Direct Laser-Induced Reduction of Graphite Oxide. The Journal of Physical Chemistry Letters, 1, 2633-2636. http://dx.doi.org/10.1021/jz100790y

[32] Zhang, Y., Guo, L., Wei, S., Hei, Y. and Sun, H. (2010) Direct Imprinting of Microcircuits on Graphene Oxides Film by Femtosecond Laser Reduction. Nano Today, 5, 15-20. http://dx.doi.org/10.1016/j.nantod.2009.12.009

[33] Trusovas, R., Raciukaitis, G., Barkauskas, J. and Mazeikiene, R. (2012) Laser Induced Graphite Oxide/Graphene Transformation. Journal of Laser Micro/Nanoengineering, 7, 49-53. http://dx.doi.org/10.2961/jlmn.2012.01.0009

[34] Kumar, P., Subrahmanyam, K.S. and Rao, C.N.R. (2011) Graphene Produced by Radiation-Induced Reduction of Graphene Oxide. International Journal of Nanoscience, 10, 559-566.

[35] Ji, T., Hua, Y., Sun, M. and Ma, N. (2013) The Mechanism of the Reaction of Graphite Oxide to Reduced Graphene Oxide under Ultraviolet Irradiation. Carbon, 54, 412-418.

[36] Gauduel, Y., Migus, A., Chambaret, J.P. and Antonetti, A. (1987) Femtosecond Reactivity of Electron in Aqueous Solutions. Revue de Physique Appliquée, 22, 1755-1759. http://dx.doi.org/10.1051/rphysap:0198700220120175500 